\title{
PSK induces apoptosis through the inhibition of activated STAT3 in human esophageal carcinoma cells
}

\author{
SEIJI UMEHARA, HITOSHI FUJIWARA, ATSUSHI SHIOZAKI, MOMOKO TODO, AKINOBU FURUTANI, \\ MASAYUKI YONEDA, ATSUSHI IKAI, HIROYUKI TADA, SHUHEI KOMATSU, DAISUKE ICHIKAWA, \\ KAZUMA OKAMOTO, TOSHIYA OCHIAI, YUKIHITO KOKUBA and EIGO OTSUJI
}

Division of Digestive Surgery, Department of Surgery, Kyoto Prefectural University of Medicine, Kyoto 602-8566, Japan

Received January 21, 2012; Accepted April 5, 2012

DOI: 10.3892/ijo.2012.1454

\begin{abstract}
PSK, a protein-bound polysaccharide, is widely used in Japan as an immunopotentiating biological response modifier for cancer patients. PSK exerts antitumor activities through stimulation of the host's immune response; however, few studies have addressed the direct actions of PSK on tumor cells. Recently, it has been found that STAT3 is aberrantly activated in various types of malignancies, and plays a crucial role in tumor cell proliferation and survival. In the present study, STAT3 was constitutively activated in KYSE170 and TE13 esophageal carcinoma cells, and PSK inhibited proliferation and induced apoptosis in these cells in a dose-dependent manner. Based on these findings, the relationship between STAT3 and apoptosis in these cells was investigated. Results showed that PSK inhibited the expression of activated STAT3 and stimulated the expression of pro-apoptotic Bax in a dose-dependent manner, without affecting the expression of anti-apoptotic Bcl-xL and Mcl-1. These results indicate that PSK may induce apoptosis in esophageal carcinoma cells by inhibiting the expression of activated STAT3.
\end{abstract}

\section{Introduction}

Esophageal cancer is one of the most malignant tumors with a highly aggressive behavior and tends to show systemic spread from an early stage, resulting in a high incidence of recurrence and poor prognosis, even if a complete resection is performed (1). Recently, chemotherapy or chemoradiotherapy has been actively performed as a preoperative or induction therapy in multimodal treatment for advanced tumors, however, the treatment outcome has not been satisfactory (2). On the other hand, tumor progression worsens the host's nutritional state and immune response, which may reduce the therapeutic intensity of conventional treat-

Correspondence to: Dr Hitoshi Fujiwara, Division of Digestive Surgery, Department of Surgery, Kyoto Prefectural University of Medicine, 465 Kajii-cho, Kawaramachi-hirokoji, Kamigyo-ku, Kyoto 602-8566, Japan

E-mail: hfuji@koto.kpu-m.ac.jp

Key words: esophageal carcinoma, polysaccharide-K, apoptosis, signal transducer and activator of transcription 3 , Bax ments (3). In addition, treatment-associated invasiveness may decrease the host's immune response and therapeutic efficacy. In such a situation, the expectation of new treatment modalities, such as molecular target therapy, has been increasing to improve the treatment outcome of esophageal cancer (4).

Polysaccharide-K (PSK), a protein-bound polysaccharide derived from the Coriolaceae mushroom, has been used as a non-specific immunostimulant for treating cancer patients in Japan for more than 30 years (5). The antitumor activity for PSK has been documented in experimental animal models and its beneficial therapeutic effects have been shown in clinical studies of several types of tumor (6). PSK has been shown to exert antitumor effects mainly through its action on the host's immune response. On the other hand, PSK has been reported to act on tumor cells themselves, thereby inducing antitumor effects (6). However, the direct action of PSK on tumor cells has been not fully understood in comparison with its action on the host's immune response.

Signal transducer and activator of transcription 3 (STAT3) has a role as a cytoplasmic mediator of cytokine signaling and nuclear transcription factor (7). The activation of STAT3 is tightly regulated under physiologic conditions in normal cells (8). Recently, it was shown that STAT3 is aberrantly activated in various types of malignancies such as leukemia, lymphoma, multiple myeloma, head and neck, breast, and prostate cancers, and plays a crucial role in tumor cell proliferation and survival, and tumor angiogenesis and invasion (9-18). In addition, recent study by Zhang et al demonstrated that PSK augments docetaxelinduced apoptosis by inhibiting NF- $\mathrm{B}$ in human pancreatic cancer cells (19). STAT3 regulates a variety of cellular behaviors in close association with NF- $\kappa \mathrm{B}$ (20). These findings strongly suggest that PSK may exert antitumor activities by acting not

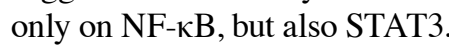

We performed an in vitro study to investigate the direct antitumor effects of PSK and its molecular mechanisms in esophageal carcinoma cell lines; the effect of PSK on cell proliferation and apoptosis focusing on its possible influence on STAT3 status.

\section{Materials and methods}

Cell lines and cell culture. The human esophageal squamous cell carcinoma cell lines, KYSE170 and TE13, were obtained from 
the Cell Resource Center for the Biomedical Research Institute of Development, Aging, and Cancer (Tohoku University, Sendai, Japan). Cells were maintained in a culture medium consisting of RPMI-1640 medium (Nacalai Tesque, Kyoto, Japan) supplemented with $100 \mathrm{IU} / \mathrm{ml}$ penicillin, $100 \mu \mathrm{g} / \mathrm{ml}$ streptomycin (Sigma, Welwyn Garden City, UK), and 10\% heat-inactivated fetal bovine serum (FBS; Cell Culture Bioscience, Nichirei Biosciences, Tokyo, Japan) at $37^{\circ} \mathrm{C}$ in a humidified atmosphere containing $5 \% \mathrm{CO}_{2}$.

Reagents. A PSK 5\% solution was generously provided by Kureha Chemical Industry (Tokyo, Japan). It was diluted to concentrations ranging from 10 to $500 \mu \mathrm{g} / \mathrm{ml}$ by culture medium. The primary antibodies were a rabbit monoclonal anti-phospho-STAT3 (Tyr705) antibody (Cell Signaling Technology, Danvers, MA, USA), rabbit polyclonal antiSTAT3 antibody (Santa Cruz Biotechnology, Santa Cruz, CA, USA), rabbit monoclonal anti-Bcl-xL antibody (Cell Signaling Technology), rabbit monoclonal anti-Mcl-1 antibody (Cell Signaling Technology), mouse monoclonal anti-Bax antibody (Santa Cruz Biotechnology), and rabbit polyclonal anti-GAPDH antibody (Santa Cruz Biotechnology).

Cell proliferation assay. Cell proliferation ability was evaluated by counting the number of cells in a 3-day cell culture. Cells $\left(1 \times 10^{5}\right.$ cells $)$ were seeded in 6 -well plates in 3 -ml culture medium and incubated in the presence of PSK $(0,10,100$, $500 \mu \mathrm{g} / \mathrm{ml}$ ) for 24,48 , and $72 \mathrm{~h}$. Cells were then collected and the number of cells was counted.

Cell viability assay. To examine the sensitivities of human esophageal carcinoma cell lines to PSK, a WST-8 colorimetric assay was performed. Cells seeded in 96-well plates $\left(1 \times 10^{3}\right.$ cells/well $)$ were incubated in the presence of PSK $(0,10$, $100,500 \mu \mathrm{g} / \mathrm{ml}$ ) for $72 \mathrm{~h}$. After incubation, $10 \mu \mathrm{l}$ of SP solution (Nacalai Tesque) was added to each well and the cells were incubated for $1 \mathrm{~h}$. Cell viability was determined by colorimetric comparison in which optical density values were read by an ELISA reader (GENios, TECAN Group Ltd., Austria) at a wavelength of $450 \mathrm{~nm}$.

Flow cytometry for cell cycle analysis. Cells ( $1 \times 10^{5}$ cells) were seeded in 6-well plates in 3-ml culture medium and preincubated for $24 \mathrm{~h}$. PSK $(0,100 \mu \mathrm{g} / \mathrm{ml})$ was added to each well and incubated for $72 \mathrm{~h}$. Cells and culture medium were retrieved from each well to $15-\mathrm{ml}$ conical tubes and were centrifuged for $5 \mathrm{~min}$ at $1,500 \mathrm{rpm}$. They were mixed with $0.2 \%$ Triton $\mathrm{X}-100$ (Nacalai Tesque) and $1 \mathrm{mg} / \mathrm{ml}$ RNase (Qiagen, Valencia, CA, USA), and stained with $0.5 \mathrm{mg} / \mathrm{ml}$ propidium iodide (Sigma) in phosphate-buffered saline (PBS) on ice. Samples were analyzed by a flow cytometer (FACScan, Becton-Dickinson, Franklin Lakes, NJ, USA) for DNA content using propidium iodide. Ten thousand events were recorded and the proportion of cells in various phases of the cell cycle was analyzed with the Mod Fit Ltd. DNA analysis software program and Cell Quest (BectonDickinson). Three independent experiments were performed for each data set.

Cell death detection by immunocytochemistry. To confirm apoptotic cell death induced by PSK, the In Situ Cell Death
Detection kit (Roche, Lewes, UK), an immunocytochemical method to identify free 3'-OH ends localized in apoptotic bodies, was used. Direct fluorescence cytochemistry for TUNEL staining was performed using fluorescein TdT. Cells were incubated in the absence or presence of PSK $(100 \mu \mathrm{g} / \mathrm{ml})$ in 6-well plates until $50 \%$ confluence. Media were aspirated from plates, and cells were washed twice with PBS and fixed with $4 \%$ paraformaldehyde solubilized in $0.1 \%$ Triton X-100 in $0.1 \%$ sodium citrate for $60 \mathrm{~min}$ at room temperature. Cells were washed twice with PBS and incubated with TUNEL reaction mixture for $60 \mathrm{~min}$ at $37^{\circ} \mathrm{C}$ in $5 \% \mathrm{CO}_{2}$. Cells were again washed twice with PBS and analyzed by fluorescence microscopy (IX70, Olympus, Tokyo, Japan).

Assay for STAT3 phosphorylation. STAT3 phosphorylation was analyzed using a Cellular Activation of Signaling ELISA kit (CASE Kit: SuperArray Biosciences, Frederick, $\mathrm{MD)}$ according to the manufacturer's instructions with some minor modifications. Cells $\left(1.5 \times 10^{4}\right.$ cells $)$ were seeded in 96-well plates, cultured for $24 \mathrm{~h}$, and were treated with PSK $(0,10,100 \mu \mathrm{g} / \mathrm{ml})$ for $60 \mathrm{~min}$. Cells were then fixed with $4 \%$ formaldehyde for $20 \mathrm{~min}$ and processed for ELISA measurements with anti-pY705-STAT3 or anti-STAT3 antibodies. The bound antibodies were then detected with developing solution. Plates were analyzed using an ELISA reader at a wavelength of $450 \mathrm{~nm}$. After washing twice with washing buffer, plates were treated with cell staining buffer, and read in an ELISA reader at a wavelength of $595 \mathrm{~nm}$. Readings were taken to assess the total number of cells per well and these data were normalized for the number of cells in each well.

Western blot analysis. The protein expressions of Bax, Bcl-xL, Mcl-1, p-STAT3, and STAT3 were examined by western blot analysis, and equal protein loading was evaluated by GAPDH. Cultured cells treated with PSK $(0,10,100 \mu \mathrm{g} / \mathrm{ml})$ for $48 \mathrm{~h}$ were collected and lysed with a lysis buffer for $60 \mathrm{~min}$ at $4^{\circ} \mathrm{C}$, and debris was eliminated by centrifugation at $15000 \mathrm{rpm}$ for $30 \mathrm{~min}$ at $4^{\circ} \mathrm{C}$. The supernatant was collected and the protein concentration of each sample was measured by a protein assay rapid kit (Wako, Osaka, Japan). Equal amounts of protein $(50 \mu \mathrm{g})$ were mixed with SDS sample buffer containing 2-mercaptoethanol, boiled for $5 \mathrm{~min}$, and loaded on 10\% SDS-PAGE gels. It was transferred to polyvinylidene difluoride (PVDF) membranes (GE Healthcare, Milwaukee, WI, USA) with a tank transfer system (Bio-Rad). Membranes for the antibody reaction of Bax, Bcl-xL, Mcl-1, STAT3, and GAPDH were blocked in 5\% skimmed milk in TBS-T at room temperature for $1 \mathrm{~h}$. Membranes for the antibody reaction of p-STAT3 were blocked in Blocking One-P (Nacalai Tesque) designed for applications with phospho-specific antibodies. Membranes were reacted with specific primary antibodies diluted as follows: Bax was 1:500, Bcl-xL was 1:1000, Mcl-1 was 1:1000, p-STAT3 was 1:1000, STAT3 was 1:500, and GAPDH was 1:500 at room temperature for $1 \mathrm{~h}$. The bound primary antibody was detected by either antirabbit or anti-mouse IgG conjugated to horseradish peroxidase (HRP). Signals were detected with ECL and western blotting detection reagents (GE Healthcare UK Limited, UK).

Statistical analysis. Data were reported as the mean \pm standard deviation of triplicate experiments. A Student's t-test was used 
A. KYSE170

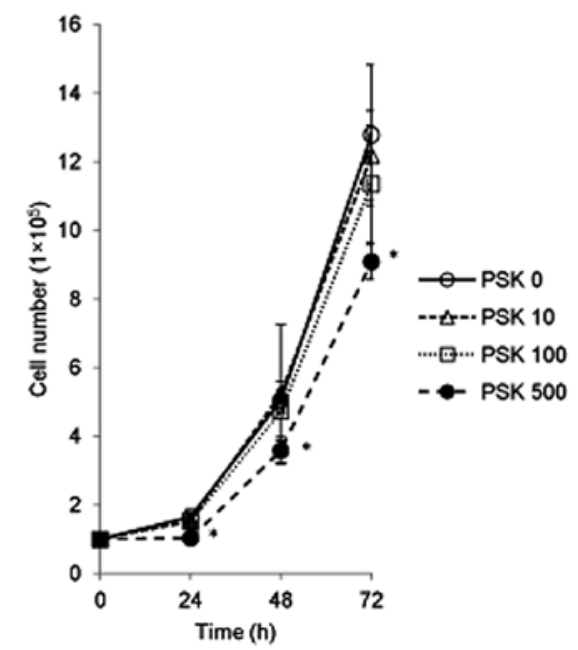

C. KYSE170

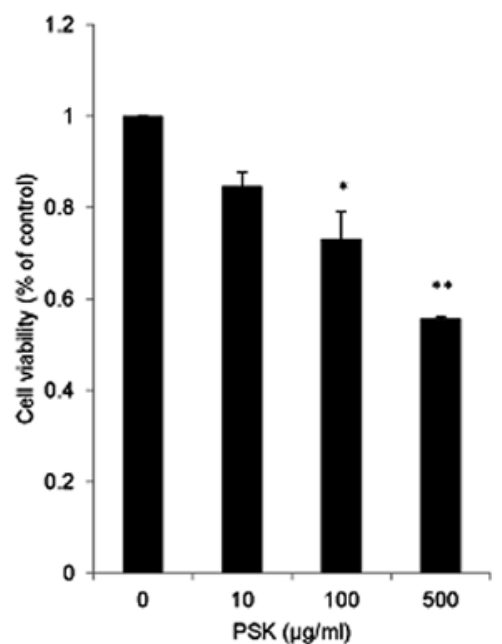

B. TE13

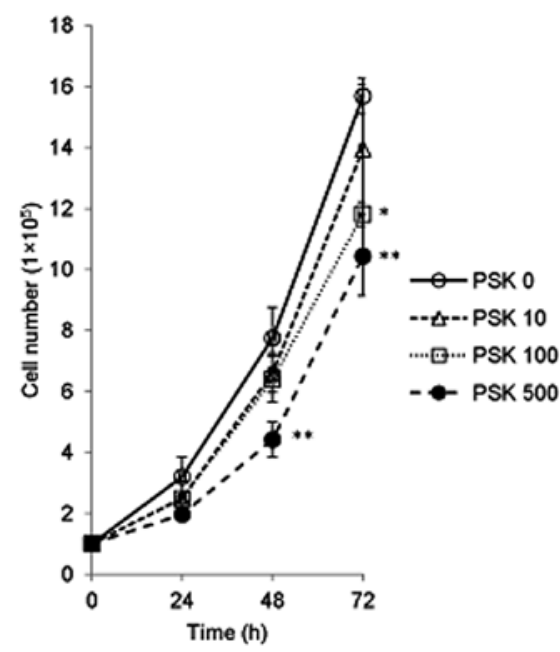

D. TE13

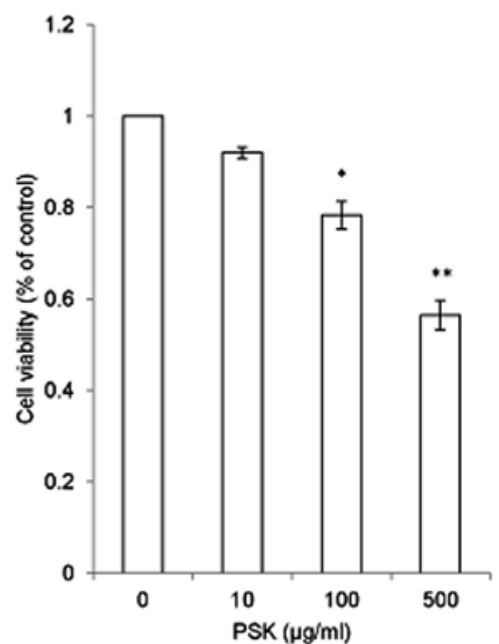

Figure 1. Effect of PSK on cell proliferation and viability. KYSE170 and TE13 cells were incubated with PSK at the indicated concentrations. Cell proliferation was assessed by cell counting. Cell viability was assessed by a WST- 8 assay $\left({ }^{*} \mathrm{p}<0.05,{ }^{* *} \mathrm{p}<0.01\right)$.

for statistical comparisons. $\mathrm{p}<0.05$ was considered significant. ${ }^{*} \mathrm{p}<0.05$ vs. control. ${ }^{* *} \mathrm{p}<0.01$ vs. control.

\section{Results}

Effect of PSK on cell growth and viability. In the cell growth assay, the cell growth ability of both cell lines was suppressed dose-dependently by PSK. In KYSE170 cells, the cell numbers at doses of 100 and $500 \mu \mathrm{g} / \mathrm{ml}$ of PSK after 72-h incubation was $88.8 \%$ and $71.1 \%$ of the control, respectively (Fig. 1A). A significant difference was observed between the control and PSK-treated groups $(500 \mu \mathrm{g} / \mathrm{ml}, \mathrm{p}<0.05)$. In TE13 cells, the cell numbers at doses of 10,100, and $500 \mu \mathrm{g} / \mathrm{ml}$ of PSK after 72-h incubation was $89.0 \%, 75.3 \%$, and $66.5 \%$ of the control, respectively (Fig. 1B). Significant differences were observed at 100 and $500 \mu \mathrm{g} / \mathrm{ml}$ of PSK ( $<<0.05,0.01$, respectively). Similarly, in the WST-8 assay, cell viability was suppressed dose-dependently by PSK. In KYSE170 cells, cell viability at doses of 10, 100, and $500 \mu \mathrm{g} / \mathrm{ml}$ of PSK was $84.7 \pm 2.9,73.1 \pm 5.9$, and $55.6 \pm 0.5 \%$ of control, respectively (Fig. 1C). In TE13 cells, cell viability at doses of 10,100 , and $500 \mu \mathrm{g} / \mathrm{ml}$ of PSK was $91.9 \pm 1.2 \%$, $78.2 \pm 3.0 \%$, and $56.4 \pm 3.2 \%$ of the control, respectively (Fig. 1D). In both cell lines, significant differences were observed between control and PSK-treated cells at 100 and $500 \mu \mathrm{g} / \mathrm{ml}$ of PSK $(\mathrm{p}<0.05,0.01$, respectively).

Detection of apoptosis induced by PSK. Apoptotic cell death induced by PSK was evaluated by cell cycle analysis and immunocytochemistry. In cell cycle distribution, the proportion of sub-G1 cells, which indicates the apoptotic cell population, was $3.06 \%$ and $1.31 \%$ in the absence of PSK in KYSE170 and TE13, respectively, whereas the proportion increased to $5.21 \%$ and $4.14 \%$ in the presence of PSK $(100 \mu \mathrm{g} / \mathrm{ml})$ in KYSE170 and TE13, respectively (Fig. 2). In addition, PSK-induced apoptotic cells were morphologically detected by phase contrast microscopy and immunocytochemically detected as TUNEL-positive cells under fluorescence microscopic observation (Fig. 3). 

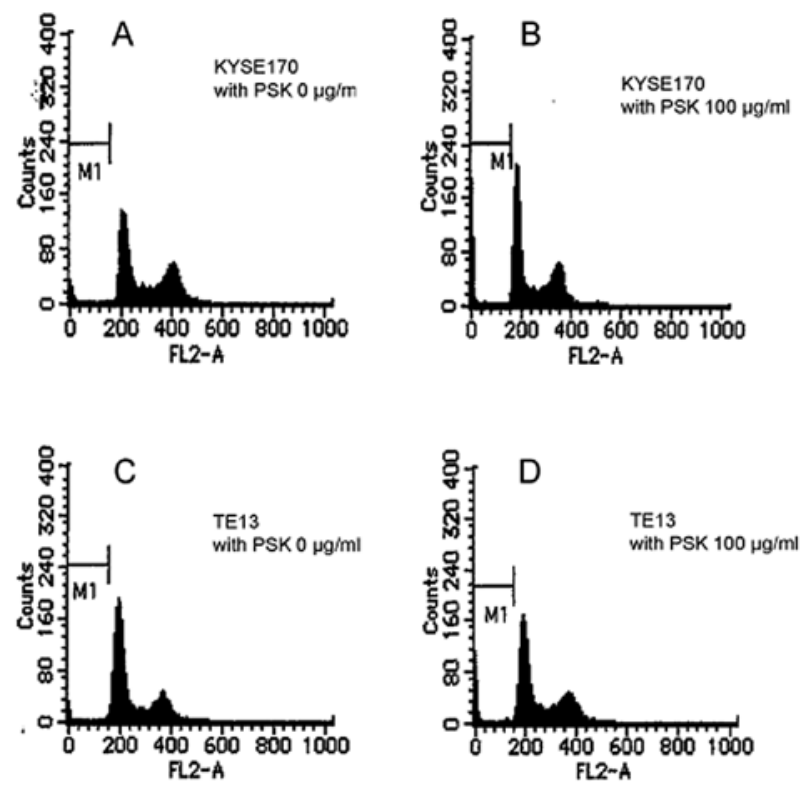

E

\begin{tabular}{cccccc}
\hline Cell line & $\begin{array}{c}\text { PSK } \\
(100 \mu \mathrm{g} / \mathrm{ml})\end{array}$ & $\begin{array}{c}\text { sub G1 } \\
(\%)\end{array}$ & G1 (\%) & S $(\%)$ & G2/M (\%) \\
\hline \multirow{2}{*}{ KYSE170 } & - & 3.06 & 40.15 & 35.96 & 23.90 \\
& + & 5.21 & 44.26 & 36.13 & 19.61 \\
\hline \multirow{2}{*}{ TE13 } & - & 1.31 & 60.05 & 24.55 & 15.40 \\
& + & 4.14 & 46.68 & 33.33 & 19.99 \\
\hline
\end{tabular}

Figure 2. Effect of PSK on cell cycle distribution and apoptosis. KYSE170 and TE13 cells treated with $100 \mu \mathrm{g} / \mathrm{ml}$ of PSK were analyzed by flow cytometry to assess cell cycle distribution and apoptosis. The M1 fraction indicates the sub-G1 apoptotic cell population. The percentage of each cell cycle population (sub-G1, G1, S, and G2-M) are shown in (E).

Effect of PSK on STAT3 phosphorylation. When evaluated by ELISA, STAT3 was constitutively phosphorylated in both cell lines. The total amount of STAT3 was not affected by PSK, whereas phosphorylated STAT3 was decreased by PSK in a dose-dependent manner (Fig. 4A and B). Similarly, when evaluated by western blot analysis, p-STAT3 expression was decreased by PSK treatment in a dose-dependent manner, although STAT3 expression was not affected by PSK treatment (Fig. 4C).

Effect of PSK on Bcl-2 family protein expression. The effect of PSK on the expression of Bcl-2 family proteins (anti-apoptotic Bcl-xL and Mcl-1, and pro-apoptotic Bax) was investigated by western blot analysis. In both cell lines, Bax expression was increased by PSK in a dose-dependent manner, whereas Bcl-xL and Mcl-1 expression was not affected by PSK (Fig. 5).

\section{Discussion}

PSK, an orally administered biological response modifier, has been shown to be more effective in prolonging the survival of
A $\quad$ KYSE170 with PSK $100 \mu \mathrm{g} / \mathrm{ml}$ B

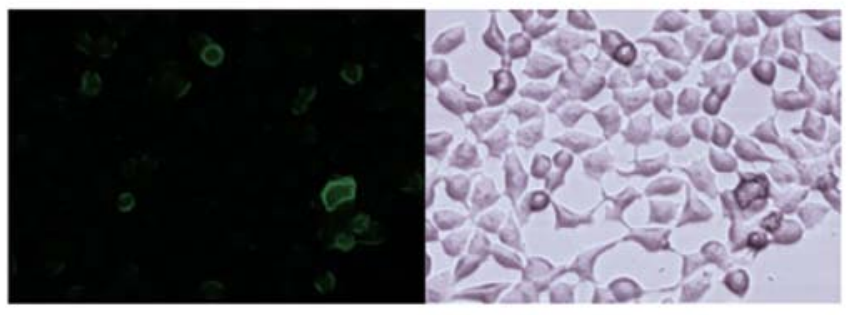

C TE13 with PSK $100 \mu \mathrm{g} / \mathrm{ml}$ D

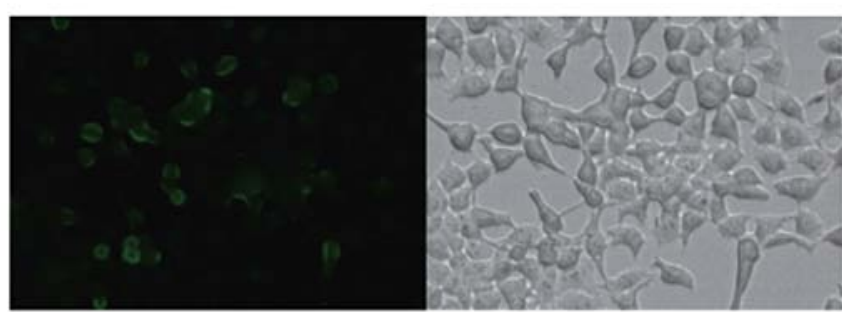

Direct fluorescence

Phase contrast

Figure 3. Immunocytochemical detection of PSK-induced apoptotic cells. KYSE170 and TE13 cells were treated with $100 \mu \mathrm{g} / \mathrm{ml}$ of PSK. Cells were then treated for the fluorescent detection of apoptotic cells according to the method described in Materials and methods. Fluorescence (A and C) and phase-contrast (B and D) views of the identical microscopic field of KYSE170 (A and B) and TE13 (C and D) cells are shown.

patients with gastric cancer or colorectal cancer after a curative resection by its combination use with chemotherapy compared with chemotherapy alone $(21,22)$. The anti-tumor effects of PSK have been analyzed, with a focus mainly on its action on the host's immune response such as cytokine induction in human peripheral blood mononuclear cells, enhancement of the cytotoxicity of human tumor infiltrating lymphocytes, and inhibition of plasma TGF- $\beta$ levels in tumor-bearing mice (23-25). On the other hand, there are several studies on the direct action of PSK on tumor cells; MMP inhibition and suppression of invasion in gastric carcinoma cells; G1 arrest in gastric carcinoma cells; enhancement of the expression of major histocompatibility complex (HLA) class I; and apoptosis induction in leukemia and lymphoma cells (26-30). The present study demonstrated that PSK suppressed cell proliferation and induced apoptosis in esophageal carcinoma cells, and inhibition of activated STAT3 and induction of pro-apoptotic Bax played a role in apoptosis induction.

With regard to the causal relationship between STAT3 inhibition and apoptosis, STAT3 inhibition by a selective STAT3 inhibitor has been shown to induce apoptosis in various carcinoma cells (31-33). Nielsen et al reported that inhibition of STAT3 phosphorylation by a JAK kinase inhibitor increased Bax expression, decreased Bcl-2 expression, and induced apoptosis in mycosis fungoides tumor cells (33). This suggests that PSK-mediated inhibition of STAT3 may regulate the expression of Bcl-2 family proteins. Bcl-2 family proteins consist of anti-apoptotic molecules such as Bcl-2, Bcl-xL, and Mcl-1, and pro-apoptotic molecules, such as Bax, Bad, and Bak, and the expression ratio of pro-apoptotic to anti-apoptotic proteins is 
A. KYSE170

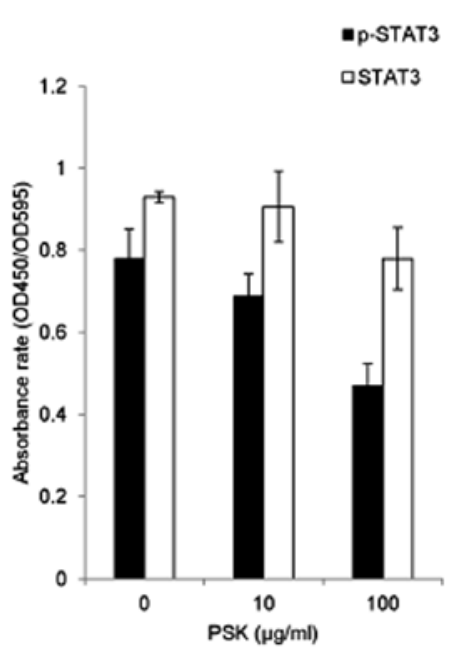

B. TE13

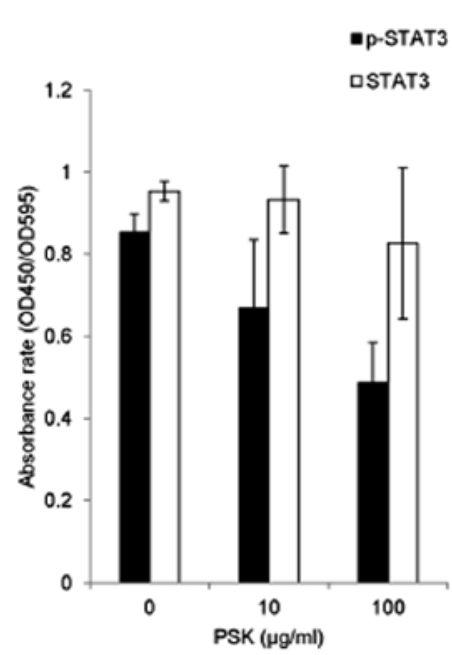

C

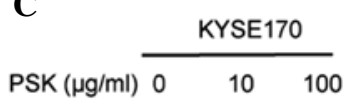

p-STAT3 $\square$

STAT3

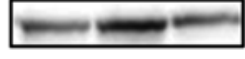

GAPDH

Figure 4. Effect of PSK on STAT3 expression. KYSE170 and TE13 cells were treated with PSK at the indicated concentrations. Total and phosphorylated STAT3 expressions were then assessed by an ELISA kit for STAT3 Y705 (A and B) and western blotting (C). GAPDH was used as an internal control.

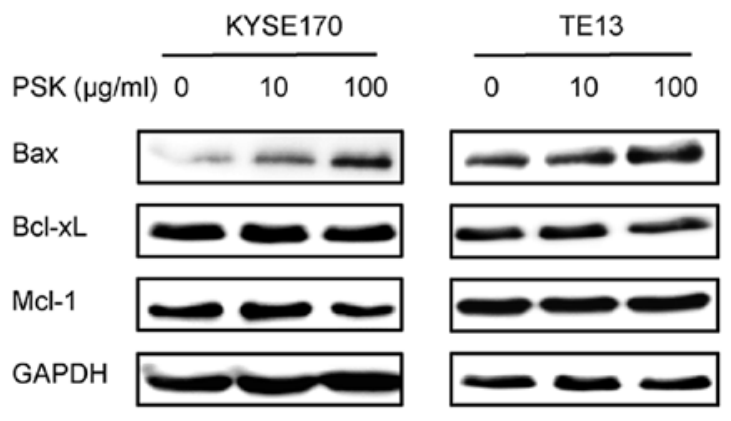

Figure 5. Effect of PSK on Bcl-2 family protein expression. KYSE170 and TE13 cells were treated with PSK at the indicated concentrations. Bax, Bcl-xL, and Mcl-1 expressions were then assessed by western blotting. GAPDH was used as an internal control.

crucial to determine survival or death following an apoptotic stimulus (34). Ye et al reported that Grifolin isolated from a mushroom (Albatrellus confluens) increased the expression ratio of $\mathrm{Bax}$ to $\mathrm{Bcl}-2$ and induced apoptosis in a human nasopharyngeal carcinoma cell line (35). In our study, PSK, a protein-bound polysaccharide isolated from the Coriolaceae mushroom, upregulated Bax expression without any substantial change in Bcl-xL or Mcl-1 expression, and induced apoptosis in esophageal carcinoma cell lines with a subsequent increase in the ratio of pro-apoptotic to anti-apoptotic proteins. PSK is considered to be a multi-molecular target drug according to its molecular structure. This suggests that PSK may act independently on STAT3 and Bcl-2 family proteins. PSK-mediated actions on STAT3 and Bcl-2 family proteins may collectively determine the expression status of Bcl-2 family proteins.

In conclusion, the present study demonstrated that PSK inhibited cell proliferation and induced apoptosis in esophageal carcinoma cell lines through STAT3 inhibition and Bax augmentation. PSK exerts dual antitumor effects by not only stimulating the host's immune response, but also acting on tumor cells, which is a unique characteristic distinct from recent molecular target drugs. Blocking STAT3 signaling in tumor cells has been shown to induce apoptosis, inhibit cell proliferation, suppress angiogenesis, and stimulate immune responses (36-38). Accordingly, our present study on PSK-mediated antitumor effects focusing on STAT3 signaling will provide useful information for the introduction of molecular target therapy into conventional treatment modalities for esophageal cancer.

\section{References}

1. Sugimachi K, Inokuchi K, Kuwano H, Kai H, Okamura T and Okudaira Y: Patterns of recurrence after curative resection for carcinoma of the thoracic part of the esophagus. Surg Gynecol Obstet 157: 537-540, 1983.

2. Enzinger PC and Mayer RJ: Esophageal cancer. N Engl J Med 349: 2241-2252, 2003

3. Tabata T, Hazama S, Yoshino S and Oka M: Th2 subset dominance among peripheral blood $\mathrm{T}$ lymphocytes in patients with digestive cancers. Am J Surg 177: 203-208, 1999.

4. Tew WP, Kelsen DP and Ilson DH: Targeted therapies for esophageal cancer. Oncologist 10: 590-601, 2005.

5. Tsukagoshi S, Hashimoto Y, Fujii G, Kobayashi H, Nomoto K and Orita K: Krestin (PSK). Cancer Treat Rev 11: 131-155, 1984.

6. Fisher M and Yang LX: Anticancer effects and mechanisms of polysaccharide-K (PSK): implications of cancer immunotherapy. Anticancer Res 22: 1737-1754, 2002.

7. Bromberg J and Darnell JE Jr: The role of STATs in transcriptional control and their impact on cellular function. Oncogene 19: 2468-2473, 2000.

8. Krebs DL and Hilton DJ: SOCS proteins: negative regulators of cytokine signaling. Stem Cells 19: 378-387, 2001.

9. Song JI and Grandis JR: STAT signaling in head and neck cancer. Oncogene 19: 2489-2495, 2000.

10. Garcia R, Bowman TL, Niu G, et al: Constitutive activation of Stat 3 by the Src and JAK tyrosine kinases participates in growth regulation of human breast carcinoma cells. Oncogene 20: 2499-2513, 2001.

11. Weber-Nordt RM, Egen C, Wehinger J, et al: Constitutive activation of STAT proteins in primary lymphoid and myeloid leukemia cells and in Epstein-Barr virus (EBV)-related lymphoma cell lines. Blood 88: 809-816, 1996.

12. Sumita N, Bito T, Nakajima $K$ and Nishigori C: Stat3 activation is required for cell proliferation and tumorigenesis but not for cell viability in cutaneous squamous cell carcinoma cell lines. Exp Dermatol 15: 291-299, 2006.

13. Suiqing C, Min Z and Lirong C: Overexpression of phosphorylatedSTAT3 correlated with the invasion and metastasis of cutaneous squamous cell carcinoma. J Dermatol 32: 354-360, 2005. 
14. Catlett-Falcone R, Landowski TH, Oshiro M, et al: Constitutive activation of Stat 3 signaling confers resistance to apoptosis in human U266 myeloma cells. Immunity 10: 105-115, 1999.

15. Judd LM, Bredin K, Kalantzis A, Jenkins BJ, Ernst M and Giraud AS: STAT3 activation regulates growth, inflammation, and vascularization in a mouse model of gastric tumorigenesis. Gastroenterology 131: 1073-1085, 2006.

16. Gritsko T, Williams A, Turkson J, et al: Persistent activation of Stat 3 signaling induces survivin gene expression and confers resistance to apoptosis in human breast cancer cells. Clin Cancer Res 12: 11-19, 2006.

17. Bromberg JF, Wrzeszczynska MH, Devgan G, et al: Stat3 as an oncogene. Cell 98: 295-303, 1999.

18. Niu G, Wright KL, Huang M, et al: Constitutive Stat3 activity up-regulates VEGF expression and tumor angiogenesis. Oncogene 21: 2000-2008, 2002.

19. Zhang H, Morisaki T, Nakahara C, et al: PSK-mediated NF-kappaB inhibition augments docetaxel-induced apoptosis in human pancreatic cancer cells NOR-P1. Oncogene 22: 2088-2096, 2003.

20. Grivennikov SI and Karin M: Dangerous liaisons: STAT3 and NF-kappaB collaboration and crosstalk in cancer. Cytokine Growth Factor Rev 21: 11-19, 2010.

21. Nakazato H, Koike A, Saji S, Ogawa N and Sakamoto J: Efficacy of immunochemotherapy as adjuvant treatment after curative resection of gastric cancer. Study Group of Immunochemotherapy with PSK for Gastric Cancer. Lancet 343: 1122-1126, 1994.

22. Ohwada S, Ikeya T, Yokomori T, et al: Adjuvant immunochemotherapy with oral Tegafur/Uracil plus PSK in patients with stage II or III colorectal cancer: a randomised controlled study. Br J Cancer 90: 1003-1010, 2004

23. Hirose K, Zachariae CO, Oppenheim JJ and Matsushima K Induction of gene expression and production of immunomodulating cytokines by PSK in human peripheral blood mononuclear cells. Lymphokine Res 9: 475-483, 1990.

24. Noguchi K, Tanimura H, Yamaue H, et al: Polysaccharide preparation PSK augments the proliferation and cytotoxicity of tumor-infiltrating lymphocytes in vitro. Anticancer Res 15 : 255-258, 1995

25. Harada M, Matsunaga K, Oguchi Y, et al: Oral administration of PSK can improve the impaired anti-tumor $\mathrm{CD}^{+} \mathrm{T}$-cell response in gut-associated lymphoid tissue (GALT) of specific-pathogenfree mice. Int J Cancer 70: 362-372, 1997.

26. Zhang H, Morisaki T, Matsunaga $\mathrm{H}$, et al: Protein-bound polysaccharide PSK inhibits tumor invasiveness by down-regulation of TGF-beta1 and MMPs. Clin Exp Metastasis 18: 343-352, 2000 .
27. Jiménez-Medina E, Berruguilla E, Romero I, et al: The immunomodulator PSK induces in vitro cytotoxic activity in tumour cell lines via arrest of cell cycle and induction of apoptosis. BMC Cancer 8: 78, 2008.

28. Iguchi C, Nio Y, Takeda $\mathrm{H}$, et al: Plant polysaccharide PSK: cytostatic effects on growth and invasion; modulating effect on the expression of HLA and adhesion molecules on human gastric and colonic tumor cell surface. Anticancer Res 21: 10071013, 2001

29. Hirahara N, Fujioka M, Edamatsu T, et al: Protein-bound polysaccharide-K (PSK) induces apoptosis and inhibits proliferation of promyelomonocytic leukemia HL-60 cells. Anticancer Res 31: 2733-2738, 2011

30. Yefenof E, Gafanovitch I, Oron E, Bar M and Klein E: Prophylactic intervention in radiation-leukemia-virus-induced murine lymphoma by the biological response modifier polysaccharide K. Cancer Immunol Immunother 41: 389-396, 1996.

31. Lin L, Hutzen B, Li PK, et al: A novel small molecule, LLL12, inhibits STAT3 phosphorylation and activities and exhibits potent growth-suppressive activity in human cancer cells. Neoplasia 12 : 39-50, 2010.

32. Iwamaru A, Szymanski S, Iwado E, et al: A novel inhibitor of the STAT3 pathway induces apoptosis in malignant glioma cells both in vitro and in vivo. Oncogene 26: 2435-2444, 2007.

33. Nielsen M, Kaestel CG, Eriksen KW, et al: Inhibition of constitutively activated Stat 3 correlates with altered Bcl-2/Bax expression and induction of apoptosis in mycosis fungoides tumor cells. Leukemia 13: 735-738, 1999.

34. Oltvai ZN, Milliman CL and Korsmeyer SJ: Bcl-2 heterodimerizes in vivo with a conserved homolog, Bax, that accelerates programmed cell death. Cell 74: 609-619, 1993.

35. Ye M, Liu JK, Lu ZX, et al: Grifolin, a potential antitumor natural product from the mushroom Albatrellus confluens, inhibits tumor cell growth by inducing apoptosis in vitro. FEBS Lett 579: 3437-3443, 2005.

36. Yu H and Jove R: The STATs of cancer - new molecular targets come of age. Nat Rev Cancer 4: 97-105, 2004.

37. Bowman T, Garcia R, Turkson J and Jove R: STATs in oncogenesis. Oncogene 19: 2474-2488, 2000.

38. Buettner R, Mora LB and Jove R: Activated STAT signaling in human tumors provides novel molecular targets for therapeutic intervention. Clin Cancer Res 8: 945-954, 2002. 